\title{
Measuring receptive collocational competence across proficiency levels
}

\section{Déogratias Nizonkiza}

School of Languages, Potchefstroom Campus, North-West University, South Africa | Department of English Language and Literature, Université du Burundi

E-mail: deo.nizonkiza@nwu.ac.za

\begin{abstract}
The present study investigates (i) English as Foreign Language (EFL) learners' receptive collocational knowledge growth in relation to their linguistic proficiency level; (ii) how much receptive collocational knowledge is acquired as linguistic proficiency develops; and (iii) the extent to which receptive knowledge of collocations of EFL learners varies across word frequency bands. A proficiency measure and a collocation test were administered to English majors at the University of Burundi. The results of the study suggest that receptive collocational competence develops alongside EFL learners' linguistic proficiency, which lends empirical support to Gyllstad (2007, 2009) and Nizonkiza (2011), among others, who reported similar findings. Furthermore, EFL learners' collocational knowledge growth seems to be quantifiable, where both linguistic proficiency level and word frequency occupy crucial roles. While more collocational gains that EFL learners could potentially add as a result of change in proficiency are found at lower levels of proficiency, collocations of words from more frequent word bands seem to be mastered first, and more gains are found at more frequent word bands. These results confirm earlier findings on the non-linear nature of vocabulary growth (cf. Meara 1996) and the fundamental role played by frequency in word knowledge for vocabulary in general (Nation 1983, 1990; Nation and Beglar 2007), which are extended here to include collocational knowledge.
\end{abstract}

Keywords: receptive knowledge of collocations, English as Foreign Language, linguistic proficiency, word frequency

\section{Introduction}

Collocations are lexical combinations preferred by native speakers of a language - in this case English - e.g. say a prayer, draw a conclusion, make a mistake, do justice, and lose count rather than *tell a prayer, *pull a conclusion, *do a mistake, *make justice and *drop count ${ }^{1}$, respectively. Collocations have increasingly attracted research attention over the past few years (Barfield and Gyllstad 2009). Scholars such as Pawley and Syder (1983) and Wray (2002), among

\footnotetext{
${ }^{1}$ These examples were taken from Gyllstad (2007: 1-2).
} 
others, have convincingly demonstrated that collocations are important in second language (L2) and foreign language (FL) contexts as they help users to achieve fluency and thus sound nativelike. Pawley and Syder (1983: 192), for instance, state that "[t]he stock of lexicalized sentence stems known to the ordinary mature speaker of English amounts to hundreds of thousands". For them, these lexicalised and semi-lexicalised sentences, which are retrieved as wholes, facilitate fluency. This view is supported by empirical evidence from scholars who have attempted to examine the relationship between collocations and L2/FL proficiency, among other things. Boers, Eyckmans, Kappel, Stengers and Demecheleer (2006), for instance, have established a relationship between collocational competence and oral proficiency among EFL learners. Many other studies have also revealed that collocations can indeed characterise L2/FL proficiency (see, among others, Granger 1998; Granger and Meunier 2008; Gyllstad 2007, 2009; Howarth 1998; Keshavarz and Salimi 2007; Meunier and Granger 2008; Mochizuki 2002; Nesselhauf 2005; Nizonkiza 2011; Schmitt 1998).

The relationship between knowledge of collocations and linguistic proficiency has been established through (receptive or productive) testing, which has proven to be an excellent way of understanding collocations (Gyllstad 2007). Methods adopted include essay analysis, translation, cloze procedures, and recall and recognition tasks. The receptive tests - especially those which associate collocations with L2/FL proficiency - are relevant to this study as the aim here is to measure receptive knowledge of collocations. Barfield (2003), Gyllstad (2007, 2009), Keshavarz and Salimi (2007), Mochizuki (2002) and Nizonkiza (2011) - all reviewed in section 2.2 - are cases in point as all of these studies, with the exception of Barfield (2003), have pointed to the same general tendency that L2/FL proficiency can be predicted on the basis of collocational competence. This is an interesting finding in that even though the studies testing receptive knowledge of collocations did so with different approaches and involved students from completely different backgrounds, they are consistent in terms of the finding that a predictive relationship exists between knowledge of collocations and overall proficiency.

However, it is worth noting that these studies have several limitations which, once transcended, could allow for a full exploration of the relationship between receptive knowledge of collocations and L2/FL proficiency. These limitations range from testing collocational knowledge and another aspect of vocabulary knowledge in the same test battery (e.g. Mochizuki 2002 and Nizonkiza 2011 ) to testing different types of collocations measured in the same test battery (Keshavarz and Salimi 2007) through not embedding collocations in a context (e.g. Gyllstad 2007, 2009; Keshavarz and Salimi 2007; Nizonkiza 2011). It is my opinion that testing collocations together with another aspect of vocabulary knowledge or testing two types of collocations in the same test battery may negatively impact the test-takers' performance. It may indeed make the task harder or confusing, which may consequently also affect test-takers' performance. This may result in the omission of important information, thereby limiting the generalisability of the results. The same holds true for not providing context which is vital for word knowledge/meaning but often overlooked in vocabulary testing (Read 1997, 2000). Furthermore, none of these studies attempted to estimate the gains made in terms of collocational growth from one level of proficiency to another. Until now, we cannot tell from empirical evidence the amount of collocational knowledge learners are expected to have at different learning stages. This is a gap which I believe should be bridged and which the present study sets out to do. It falls in this endeavour to shed more light on our understanding of the association between receptive knowledge of collocations and overall linguistic proficiency, and thus complements the studies referred to above. 
This study endorses Gyllstad's (2007, 2009) view of testing collocations within a single construct, and complements it through the provision of authentic material by embedding collocations within a sentential context. Word frequency bands and their role in collocational knowledge are also considered. The study thus attempts to explore the relationship between receptive collocational competence and EFL proficiency while attempting to quantify knowledge of collocational growth as proficiency increases and across word frequency bands. The following questions are addressed:

(i) Does receptive knowledge of collocations grow with EFL linguistic proficiency?

(ii) Can receptive collocational competence be quantified across proficiency levels?

(iii) Does word frequency play a role in receptive collocational competence growth?

The study was undertaken with the following assumptions in mind:

(i) Receptive collocational competence grows parallel with linguistic proficiency (cf. Gyllstad 2007, 2009; Keshavarz and Salimi 2007; Nizonkiza 2011).

(ii) Receptive collocational competence is quantifiable, but the amount of collocational gains from one level of proficiency to another is not exactly the same. The non-linear nature of vocabulary learning in general (Meara 1996, Laufer 1998, Laufer and Paribakht 1998, Read 2004) inspired this assumption.

(iii) Word frequency plays an important role in receptive collocational competence. Nation (1983, 1990) and Nation and Beglar (2007), for example, have found that lexical competence in general varies according to word frequency bands. It is logical then to assume that the same holds for receptive knowledge of collocations.

\section{Related literature}

\subsection{Definition of collocations}

Defining collocations did not seem to be an easy task for researchers, as the available literature indicates. Wray (2002), for instance, reports a terminological problem and complains about the various terms used to refer to this phenomenon of co-occurring words and fixed expressions. She adopts the term "formulaic language" (Wray 2002: 9) which she defines as follows:

[A] sequence, continuous or discontinuous, of words or other elements, which is, or appears to be, prefabricated: that is, stored and retrieved whole from memory at the time of use, rather than being subject to generation or analysis by the language grammar.

The main idea in Wray's definition is that formulaic language consists of units of language or expressions which are stored and retrieved as wholes rather than generated by the rules of grammar. While she places importance on the wholeness of the co-occurring words in terms of storage and retrieval, Sinclair's (1991: 170) definition of collocation, which is "the occurrence of two or more words, within a short space of each other in a text", introduces the notion of 'space' between co-occurring words or, as he calls it, "span" (Sinclair 1991: 170). A span can go up to approximately four words. In the example All three methods yielded identical results, 
the word yielded collocates with results in a span of one word as they do not follow each other ${ }^{2}$. Sinclair has also introduced the notion of a main word and a co-occurring word in a collocation, respectively referred to as a "node" and a "collocate". In the above example, the node is results while the collocate is yielded, and the two collocate in the verb-noun $(\mathrm{V}+\mathrm{N})$ combination. Nattinger and DeCarrico (1992: 20) have retained the notions of 'node', 'span' and 'collocate' to which they have added the notion of 'direction' of the collocation, 'frequency', and 'fixedness':

[...] a collocational unit consists of a 'node' that co-occurs with a 'span' of words on either side. The span consists of particular word classes filled by specific lexical items. [...] If it is the case that the node word occurs with a span of particular words at a frequency greater than chance would predict, then the result is a collocation. The more certain the words in the span are to cooccur with the node, the more fixed and idiomatic the collocation.

Once again utilising the same example presented above, we can say that yielded collocates with results to the left, i.e. yielded appears to the left of results. But in the example Preliminary results suggest that there is no cause for concern, the word suggest collocates with results to the right, i.e. suggest appears to the right of results. The collocate appearing to the left or right of the node is what Nattinger and DeCarrico (1992) refer to as the "'span' of words on either side". Moreover, what they mean by "frequency" is that in order for co-occurring words to be considered a collocation, they must co-occur together up to a certain threshold.

For a comprehensive overview of the challenges related to defining collocations and the way they have been approached in the literature, readers are referred to Gyllstad (2007). Suffice it to say that co-occurrence of words is the main idea put forward by different scholars in their definitions of collocations. The operational definition adopted in this study is the one provided in the Oxford Collocations Dictionary for Students of English, which defines collocations as "the way words combine in a language to produce natural-sounding speech and writing" (Lea, Crowther and Dignen 2002: vii). This definition adheres to the view put forward by Nattinger and DeCarrico (1992) above but excludes idioms from the category of collocations.

\subsection{Measurability of collocations}

Since collocations gained increased research attention, they have been measured through receptive or productive tasks. The present study being receptive in nature, this section briefly discusses several previous studies which tested collocations receptively. Associating receptive collocational knowledge with L2/FL proficiency has established a predictive relationship between the two, i.e. learners who have a good command of collocations are likely to be more proficient (Gyllstad 2007, 2009; Keshavarz and Salimi 2007; Mochizuki 2002; Nizonkiza 2011).

Gyllstad (2007) developed two tests, namely COLLEX and COLLMATCH, in order to measure the receptive collocational knowledge of Swedish learners of English at different learning levels. COLLEX contains multiple-choice questions while COLLMATCH contains yes/no questions, and both tests measure $\mathrm{V}+\mathrm{N}$ collocations. The target words (nouns) were selected from the first to the fourth word families appearing in Kilgarriff's (1996, cited in Gyllstad

\footnotetext{
${ }^{2}$ The examples used here were retrieved from the Oxford Collocations Dictionary for Students of English (Lea et al. 2002).
} 
(2007)) online word-frequency list based on the British National Corpus. The Oxford Collocations Dictionary for Students of English (Lea et al. 2002) was used for collocates (verbs) selection. The collocates were cross-checked for frequency in Kilgarriff's list (1996, cited in Gyllstad (2007)). As argued by Gyllstad (2007), for testing purposes, they had to be of the same or higher frequency bands as the nodes. The tests, which Gyllstad (2009) validated, satisfactorily measured the test-takers' receptive knowledge of collocations, proved that receptive knowledge of collocations increased with learning stages, and significantly correlated with overall proficiency, depth, and vocabulary size tests. However, the tests had certain limitations, chiefly that no contextual information was provided, which might have affected the test-takers' performance.

The second study reviewed is that of Keshavarz and Salimi (2007). It tested receptive collocational competence of English majors at Tehran University, using a cloze procedure and a "fill-in-the-gaps" format. The test battery consisted of both lexical and grammatical collocations. The tests contained 50 items in a "fill-in-the-gaps" format, where three options from which to choose were provided. Lexical collocations consisted of $\mathrm{V}+\mathrm{N}$ combinations, where the verbs were omitted and had to be supplied by the test-taker. Grammatical collocations consisted of adjective-noun, noun-preposition, and verb-preposition combinations in which the adjectives and prepositions were omitted. The tests are reported to have measured what they were designed to. The tests' scores correlated well with those of the Test Of English as Foreign Language (TOEFL), a linguistic proficiency measure, which allowed the authors to conclude that receptive knowledge of collocations could be used as an indicator of L2 proficiency. However, the tests have several limitations: (i) it is not clear how and from which source the collocations were selected; (ii) the grammatical collocations are of three types and the question which can be raised is whether or not this could have impacted on the scores; and (iii), as it was reported, it is unclear whether or not the "fill-in-the-gaps" format was embedded in a context (Gyllstad 2007).

Nizonkiza (2011), of which the present study is a follow-up, investigated the relationship between lexical competence, collocational competence, and L2 proficiency. It was conducted on English majors at the University of Burundi, and utilised a test modelled on Read's (1993) Word Associates Test. The target words were selected from the Collins COBUILD Collocations Dictionary (1995) following the frequencies of individual words. The collocates of the target words were selected from the same dictionary on the basis of the frequency of co-occurrence with each node. The analytic relations, another type of associate, were selected from the Concise Oxford Dictionary (Allen 1990). The number of items totalled 50 and the test-takers were instructed to identify the associates. The study concluded that lexical competence and collocational competence could be good indicators of L2 proficiency, with the vocabulary test scores correlating well with those of the TOEFL.

One of the main limitations of the study is that collocations were not tested in a single construct. Knowledge of analytic relations was also tested in the same test battery. Furthermore, the choice of collocates was only guided by frequency, meaning that their syntactic categories were not specified. The direction of the collocations was not specified either, making the task demanding for test-takers. Like Gyllstad (2007) and Keshavarz and Salimi (2007), Nizonkiza (2011) did not provide any context, which is vital but often disregarded in vocabulary testing (Read 1997). The test thus gave a broad picture of the collocational-lexical competence and can be complemented by improving the test battery. 
Mochizuki (2002) tested receptive collocational knowledge together with paradigmatic knowledge and overall vocabulary size. Japanese first-year students participated in Mochizuki's study which aimed to explore how collocational competence and paradigmatic knowledge develop after one year of academic instruction. It is worth noting, however, that the participants were not English majors; they were majoring in other disciplines and were exposed to the language through in-class reading and conversation tasks which totalled 75 hours. The collocation test consisted of 72 words presented in multiple-choice format, where four possible options were offered to participants who were instructed to decide which option was linked to the target word in a syntagmatic (collocational) or paradigmatic (synonym or semanticallyrelated) relationship. The merit of this study is that it is longitudinal in nature as the test was presented at the beginning and at the end of the academic year. Significant differences between pre-test and post-test scores were noted, allowing Mochizuki to conclude that collocational competence increases over time, a conclusion in line with the studies which established a relationship between collocational competence and L2 proficiency.

Barfield (2003) also conducted a study on Japanese students which involved 93 undergraduate and postgraduate students. Collocations of the $\mathrm{V}+\mathrm{N}$ combination type were tested which were then compared to knowledge of the individual words constituting the collocations. The target words (40 lexical verbs) were selected from the Academic Word List (AWL; Coxhead 2000) and the General Service List (West 1953). Their collocates (three nouns for each verb) were selected from the Bank of English ${ }^{3}$. Barfield created 20 pseudo-collocates which were presented with the real collocates to the participants. Participants were required to rate their familiarity with both the real and pseudo-collocations on the following scale (cf. Gyllstad 2007: 57):

I. I don't know this combination at all.

II. I think this is not a frequent combination.

III. I think this is a frequent combination.

IV. This is definitely a frequent combination.

Barfield (2003) found that individual nouns and verbs were known almost to the same extent. However, scores on collocations were much lower, and the author concluded that knowledge of individual words does not necessarily entail recognising them in the combinations in which they are used. He also found that scores on individual words (both verbs and nouns) correlated with overall proficiency but the collocation recognition did not, thus contradicting the findings from the studies described earlier. On this basis, Gyllstad (2007) rightly observed that the relationship between receptive collocational knowledge and L2 proficiency is inconclusive. Even so, the general observation is that the relationship between collocational competence and L2 proficiency is strong.

As shown in the description above, knowledge of collocations seems to predict overall linguistic proficiency. Even though these studies were conducted in different contexts using different tasks, the general tendency they point to is an interesting finding to build on in order to advance research in this area. The general observation that there is a predictive relationship between receptive knowledge of collocations and overall proficiency has pedagogical consequences. I have in mind the response to the calls made since the 1990s for teaching L2s/FLs with the focus

\footnotetext{
${ }^{3}$ This is a huge collection of modern English that was initiated by the University of Birmingham. It is regularly updated and, to date, consists of 450 million words. It is available online at http://www.titania.bham.ac.uk/ docs/svenguide.html.
} 
on collocations (Lewis 1993, 1997, 2000; Martyńska 2004; Nation 2001; Nattinger and DeCarrico 1992; Singleton 1999; Willis 1990). L2/FL practitioners and researchers (e.g. Boers and Lindstromberg (2009) and Boers et al. (2006), amongst others) have empirically demonstrated the relevance of teaching a foreign language with explicit focus on collocations. Some of these studies have suggested approaches to adopt, of which the recent pedagogical experiments $^{4}$ (Barfield 2009, Jiang 2009, Ying and O'Neill 2009), the studies exploring and testing Lewis' (1993) Lexical Approach (Boers et al. 2006; Boers, Lindstromberg, Littlemore, Stengers and Eyckmans 2008), as well as the works reported in Wray (2002), are a few examples. The major finding is that raising learners' awareness constitutes the best way forward for teaching collocations. One general limitation of these studies, however, is that the different approaches do not relate to the frequency of words, i.e. the studies have raised learners' awareness of collocations without taking into consideration the frequency of collocation constituents. Therefore, a possible future study would have great potential if it measures collocations in relation to L2/FL proficiency and takes word frequency into account in an attempt to quantify how much knowledge is added from one level of proficiency to another.

\section{The present study}

\subsection{Sample population}

The target population of this study consists of English majors at the University of Burundi from which a sample was selected. By the time the study was conducted, the Bachelor of Arts (BA) was still a four-year degree ${ }^{5}$. The data were collected from first-, third- and fourth-year students (the second-year students were not available) towards the end of the 2009-2010 academic year. The participants were all Burundian nationals between the ages of 20 and 26. While French is their language of wider communication, they all spoke Kirundi as their mother tongue and some of them also spoke Swahili, a lingua franca of the region. Dagnelie's (1992) random sampling technique was used and the selection resulted in 115 participants.

\subsection{The test battery}

\subsubsection{Proficiency measure: TOEFL}

The TOEFL was used in this study to determine the level of EFL proficiency of the participants. The idea was to allocate test-takers to different language proficiency levels and then see whether the same levels would be reflected in the collocation test, which would therefore allow for testing of the first two assumptions of this study. The TOEFL is an internationally acknowledged English proficiency test consisting of three parts: listening comprehension, structure and written expression, and vocabulary and reading comprehension. For accessibility and practical reasons, an old paper-based version was used and the Educational Testing Service's instructions were strictly adhered to.

\footnotetext{
${ }^{4}$ Readers are referred to Wray (2002) and Barfield and Gyllstad (2009) for more details on how to teach collocations.

5 The higher education schooling system has since been reformed, and BA degrees are now three years in duration.
} 


\subsubsection{Collocation test}

For the purpose of this study, a receptive collocation test was developed. The target words were selected from Nation's (2006) word list, a database of word families ${ }^{6}$ organised in frequency bands based on the British National Corpus. Considered for selection were the 2,000-word, 3,000-word, and 5,000-word bands (cf. Nation 1983, 1990; Schmitt, Schmitt and Clapham 2001) as well as Coxhead's (2000) AWL, the latter consisting of the most frequent words in an academic context and which do not appear in the first two 1,000-word bands. The 10,000-word band, another band considered by Nation $(1983,1990)$ and Schmitt et al. (2001), was excluded from the sample because it consists of infrequent words which were deemed to be too difficult for the participants to let us learn much from the scores at this frequency band.

Ten words (cf. Nation and Beglar 2007) were selected from each word band, with Dagnelie's (1992) random sampling technique used to select the target words (nodes). Their collocates (verbs in the $\mathrm{V}+\mathrm{N}$ combination) were selected from the Oxford Collocations Dictionary for Students of English (Lea et al. 2002). Two factors guided the selection of these collocates, namely their frequency which was cross-checked in Nation (2006), and their degree of cooccurrence which was calculated using an online sampler. Ideally, the collocate had to be of a frequency level equal to or higher than the node (cf. Gyllstad 2007), with the most significant collocate selected. It is essential to note here that the collocation sampler gives different collocates of the node, indicating how often they appear in the Bank of English, how many times they co-occur with the node, and how significantly they do so.

The collocations investigated in this study were restricted to $\mathrm{V}+\mathrm{N}$ combinations for the same three reasons explained in Gyllstad (2007): (i) these combinations constitute frequent occurrences; (ii) they are more difficult for L2 learners; and (iii) they contain the most important information for communication. I have added a fourth reason, which is that when we express ourselves, we start with an object to or upon which we want to perform an action; this object is expressed through the noun. Then we think of how to perform the action, which is expressed through the verb. The result is collocation in the form of a verb paired with a noun (Lea et al. 2002). The collocations were embedded in a sentential context with the collocates omitted (see Appendix A). The test was in multiple-choice format and the test-takers' task was to supply the missing collocates, chosen from three possible options in each case: the correct collocate and two pseudo-collocates. The pseudo-collocates had a distracting "red herring" role and were all synonyms, selected from an online dictionary (Dictionary.com), of the respective collocates. The test was sent to a native English speaker, working for an examining board at Trinity College London, who confirmed the combinations as collocations. However, the distractors of the following items, which she judged as possible collocates, were changed in the final version:

(i) Item 11: honor, distractor of anniversary, was changed to label;

(ii) Item 17: construct, distractor of nest, was changed to create;

(iii) Item 18: gain, distractor of rank, was changed to strike;

(iv) Item 23: support, distractor of diversity, was changed to practise;

(v) Item 37: set up, distractor of foundations, was changed to put;

(vi) Item 39: supply, distractor of accommodation, was changed to host.

\footnotetext{
${ }^{6}$ The concept of 'word family' refers to a word and its family members, such as derivations or inflections.
} 
Test-takers were given one point per correct answer and 0 points per wrong or no answer. The whole test was graded out of 40 .

\section{Results}

\subsection{Item analysis}

Language testing practitioners suggest that a test has to be as reliable as possible (Green 2013). This entails that the test consistently measures exactly what it is was designed to. Cronbach's Alpha, which is commonly used to measure the reliability of a test, was computed for the test designed for this study. The result was an Alpha of .84 which indicates that the test is internally consistent (cf. Pallant 2007). Test items should also discriminate between test-takers who perform differently. This is measured by means of the Corrected Item-Total Correlation (CITC) which measures items on a scale from -1 to +1 , where the higher, the better. Ebel's (1979) scale, which suggests classifying items according to the following four categories, was used and the results are presented in Table 1.

- $\quad .40$ and higher: definitely good items;

- .30 to .39 : reasonably good items;

- .20 to .29: marginal items in need of improvement;

- Below .19: poor items to be revised or eliminated.

Table 1. Corrected Item-Total Correlation (CITC) on Ebel's (1979) scale

\begin{tabular}{lllll}
\hline CITC & .40 and higher & .30 to .39 & .20 to .29 & Below .19 \\
\hline Item & $5,6,9,12,13,15,16,18,20,3,4,14,17,1,2,19$, & $7,8,10,11,29$, \\
number & $21,22,23,26,28,31,33,34,35$ & $24,27,36,39$ & $25,32,40$ & $30,37,38$ \\
Total items & 18 & 8 & 6 & 8 \\
Percentage & $45 \%$ & $20 \%$ & $15 \%$ & $20 \%$ \\
\hline
\end{tabular}

The results in Table 1 show that $80 \%$ of the items function well, with only $20 \%$ ( 8 items) falling below the cut-off point of .19 therefore requiring revision. Overall, with $80 \%$ of items performing well, the test can be considered as measuring what it was intended to measure despite the few items which need revising.

\subsection{Relationship between collocation knowledge and EFL proficiency}

The present study investigated the relationship between collocational knowledge and EFL proficiency, assuming that it exists (first assumption in section 1). In order to test this assumption, the TOEFL scores were compared with the scores from the collocation test. The test-takers were divided into proficiency levels according to their TOEFL scores, which resulted in three groups: level $1(\mathrm{~N}=31)$, level $2(\mathrm{~N}=33)$, and level $3(\mathrm{~N}=33)$, with an average score of 332.55, 383.55, and 447.91, respectively. Note that some test-takers (18 in total) who did not finish either of the tests were excluded from the analysis on a case-by-case basis. The collocation test scores were calculated and were found to reflect the same three proficiency levels, with an average of 22.48 
for level 1, 26.58 for level 2, and 28.85 for level 3. A one-way ANOVA ${ }^{7}$ was performed and confirmed the differences between the groups as statistically significant (Sig. is 0.000, 2-tailed). This means that receptive knowledge of collocations gradually develops as EFL proficiency increases; this is represented graphically in Figure 1.

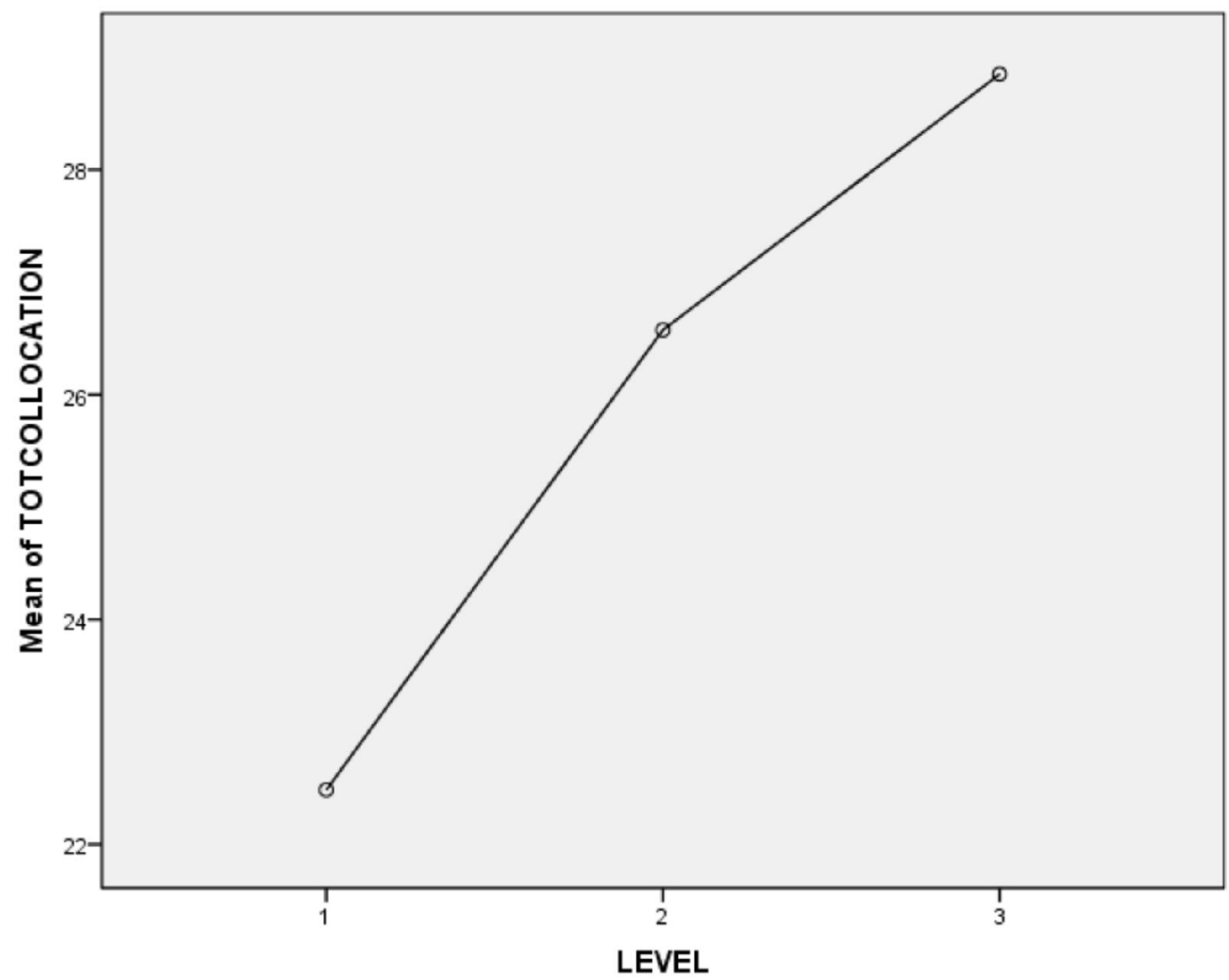

Figure 1. Collocation distinguishes between EFL proficiency levels

The collocation test and TOEFL scores were further compared by running their correlative links (Pearson correlation). The positive linear relationship between the two (Figure 2), with a significantly large correlation coefficient of .621 (cf. Appendix B), supports the above observation about a possible parallel growth between collocational knowledge and overall EFL proficiency. This is yet another argument in favour of a strong relationship between collocational competence and overall EFL proficiency.

\footnotetext{
${ }^{7}$ The one-way ANOVA is a test that assesses the statistical significance of mean differences between three or more groups (cf. Pallant 2007, among others).
} 


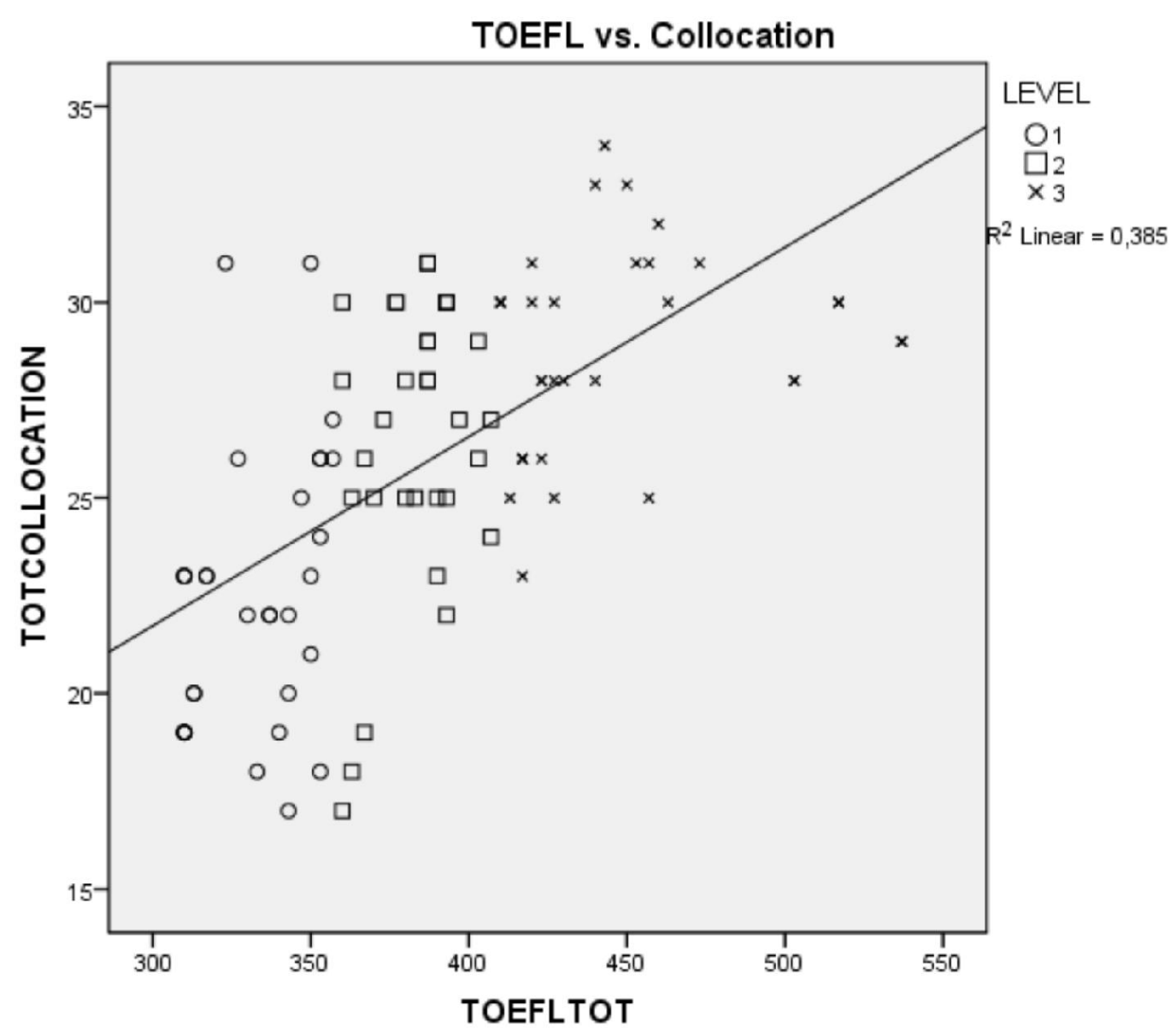

Figure 2. Correlation between TOEFL scores and the collocation test scores

The results were analysed further by performing a Scheffe analysis. This analysis complements the one-way ANOVA, of which the latter shows significant differences but does not specify which groups significantly differ. As demonstrated in Table 2, the results of the Scheffe analysis confirm that the three levels of EFL proficiency belong to three clearly different groups. This constitutes a substantial argument that the three levels of proficiency performed differently in the collocation test, meaning that one level of proficiency is different from another in terms of collocational knowledge. These findings confirm the first hypothesis of this study, namely that receptive collocational knowledge grows parallel with EFL proficiency.

Table 2. Groups distinguished by Scheffe analysis

\begin{tabular}{cccc}
\hline Proficiency levels & $\mathrm{N}$ & Mean & Groups assigned by Scheffe \\
\hline Level 1 & 31 & 22.48 & 1 \\
Level 2 & 33 & 26.58 & 2 \\
Level 3 & 33 & 28.85 & 3 \\
\hline
\end{tabular}

\subsection{Collocational growth across proficiency levels}

Collocational gains across proficiency levels constituted the second question posed in the present study. In order to quantify the collocational knowledge acquired as a result of proficiency increase, 
mean scores for collocation tests were converted into estimates of collocational size using Zhong and Hirsh's (2009) formula. Based on Schmitt and Meara's (1997) principle that "a score out of a total score at each level indicates the proportion of words the test-taker knows" (Zhong and Hirsh 2009: 97), the formula calculates the estimated size by multiplying "the target word level with the ratio between the raw score and maximum score at that level" (Zhong and Hirsh 2009: 96-97). For instance, a score of 8 out of 10 at the 2,000-word band could result in an estimate of $2,000 \times 8 \div 10=$ 1,600 words. The results presented in Table 3 clearly show that, overall, gains are observed from one level of proficiency to another. For instance, from level 1 to level 2 at the 2,000-word band, we observe a gain of 180 collocations, while that from level 2 to level 3 is 44 . It is obvious that gains from level 1 to level 2 are much higher than those from level 2 to level 3, which is consistent at the other word bands as well.

Table 3. Collocational gains across proficiency levels

\begin{tabular}{cccccccccccc}
\hline $\begin{array}{c}\text { Word } \\
\text { bands }\end{array}$ & \multirow{2}{*}{ Level 1 } & \multicolumn{2}{c}{ Level 2 } & \multicolumn{2}{c}{ Level 3 } & \multicolumn{2}{c}{ Level 1-Level } & \multicolumn{2}{c}{ Level 2-Level } \\
& Mean & Size & Mean & Size & Mean & Size & Gains & $\begin{array}{c}\text { Gain } \\
\text { size }\end{array}$ & Gains & $\begin{array}{c}\text { Gain } \\
\text { size }\end{array}$ \\
\hline 2,000 & 6.58 & 1316 & 7.48 & 1496 & 7.70 & 1540 & 0.90 & 180 & 0.22 & 44 \\
3,000 & 6.26 & 1878 & 6.91 & 2073 & 7.15 & 2145 & .65 & 195 & 0.24 & 72 \\
AWL & 5.03 & 287 & 6.27 & 357 & 7.45 & 425 & 1.24 & 70 & 1.18 & 68 \\
$4,000^{8}$ & 5.43 & 2172 & 6.41 & 2564 & 6.85 & 2740 & 0.98 & 392 & 0.44 & 176 \\
5,000 & 4.61 & 2305 & 5.91 & 2955 & 6.55 & 3275 & 1.30 & 650 & 0.64 & 320 \\
& & & & & & & & & & \\
\hline
\end{tabular}

This finding confirms the second hypothesis of the study, namely that the increase of receptive collocational competence from one level of proficiency to another can be quantified, but the amount of collocational gains is not exactly the same.

\subsection{Collocational growth across word frequency bands}

The third assumption of the study is that receptive collocational competence varies across word frequency bands, where the higher the frequency band, the higher the collocational competence. This was tested by comparing scores from the collocation test on an inter-frequency band basis. The results reveal that the scores do indeed vary according to frequency, with high scores at the 2,000 -word band, which has an average of 7.27. The scores gradually decrease with frequency (at infrequent bands) reaching 5.71 at the 5,000-word band (cf. Table 4).

Table 4. Mean scores at word frequency bands

\begin{tabular}{cccccc}
\hline Word band & Level 1 & Level 2 & Level 3 & Average & SD \\
\hline 2,000-word & 6.58 & 7.48 & 7.70 & 7.27 & 1.49 \\
3,000-word & 6.26 & 6.91 & 7.15 & 6.78 & 1.45 \\
AWL & 5.03 & 6.27 & 7.45 & 6.25 & 1.71 \\
5,000-word & 4.61 & 5.91 & 6.55 & 5.71 & 1.43 \\
\hline
\end{tabular}

\footnotetext{
${ }^{8}$ Scores at the 4,000-word band are averaged from scores at the 3,000-word and 5,000-word bands, as suggested by Laufer and Ravenhorst-Kalovski (2010).
} 
A one-way repeated ANOVA was performed which confirmed the differences as statistically significant (with a Wilks' Lambda of $0.000,2$-tailed, $p<.05$ ). In order to give estimates of the words added from one word frequency band to the next, the size estimates presented in Table 4 were used and the differences between each two successive bands are presented in Table 5 . These differences represent possible collocational gains between two word frequency bands. It should be noted that the AWL is not considered when it comes to gains estimates from one word band to another for the reason given by Laufer (1998) that words at this word band may belong to either the 4,000-word band or the 5,000-word band. On average, the gains are about 581 collocations from the 2,000-word band to the 3,000-word band, 460 collocations from the 3,000 -word band to the 4,000-word band, and 353 collocations from the 4,000-word band to the 5,000-word band. These findings indicate that more collocations are likely to be added at more frequent word bands. What we learn from these findings is that growth of receptive knowledge of collocations depends on word frequency, with massive gains at more frequent bands. This confirms the third hypothesis of the study regarding the important role played by word frequency in collocational growth.

Table 5. Collocational gains across word frequency bands

\begin{tabular}{cccc}
\hline \multicolumn{2}{c}{ Proficiency levels } & \multicolumn{2}{c}{ Collocational gains } \\
\hline & From 2,000 to 3,000 & From 3,000 to 4,000 & From 4,000 to 5,000 \\
\hline Level 1 & $1878-1316=562$ & $2172-1878=294$ & $2305-2172=133$ \\
Level 2 & $2073-1496=577$ & $2564-2073=491$ & $2955-2564=391$ \\
Level 3 & $2145-1540=605$ & $2740-2145=595$ & $3275-2740=535$ \\
Average & 581 & 460 & 353 \\
\hline
\end{tabular}

\section{Discussion and conclusion}

The present study has measured the receptive knowledge of collocations in an attempt to gauge the extent to which it grows and changes with EFL proficiency and word frequency bands. In order to test the three hypotheses put forward in the study, a proficiency test (TOEFL) and a receptive collocation test were administered to English majors at the University of Burundi.

The first hypothesis predicted that receptive collocational competence grows parallel with EFL proficiency. The results indicate that the same proficiency levels determined on the basis of the TOEFL scores were also reflected in the collocation test, with both tests correlating significantly thus confirming the hypothesis. This implies that receptive knowledge of collocations grows as a result of an increase in EFL proficiency, which supports earlier studies that pointed to similar conclusions (cf. Gyllstad 2007, 2009; Keshavarz and Salimi 2007; Nizonkiza 2011). However, as can be seen in Figure 1 and Table 3, levels 1 and 2 do not differ by the same amount of collocations as levels 2 and 3 do. The difference in terms of added collocations is much bigger between levels 1 and 2 than between levels 2 and 3 . What can be inferred from this finding is that EFL learners' receptive knowledge of collocations develops with their EFL proficiency, but significantly more so at lower levels. This confirms the second hypothesis of the study, namely that an increase in receptive collocational competence from one level of proficiency to another is measurable, but the gains from one level to another are not exactly the same. This finding empirically supports the non-linear nature of vocabulary growth (Laufer 1998, Laufer and Paribahkt 1998, Meara 1996, Melka 1997, Read 2004), but is extended to include receptive collocational knowledge. The third hypothesis tested in this study suggests that receptive 
collocational competence grows with word frequency bands. This is exactly the case, as the results indicate that the higher the word frequency band, the higher the scores. In addition, learners are likely to add more collocations at more frequent word bands. These results extend the research findings on vocabulary in general (cf. Nation 1983, 1990; Nation and Beglar 2007) to include receptive knowledge of collocations.

It should be noted that these results are not related to the teaching approaches in place at the University of Burundi. Consequently, it is difficult to account for the processes resulting in students' performances on collocation tests as shown in this study. However, knowing that collocations are not taught explicitly in any of the language programmes at the University of Burundi, a possible assumption is that growth in knowledge of collocations among these students is a result of exposure to English. Given that students do not even master collocations of words from the 2,000-word band, this approach does not contribute towards helping students develop their collocational knowledge. This study therefore joins in the calls in favour of teaching collocations explicitly. In terms of how to do so, I believe that with my conclusions regarding receptive knowledge of collocational growth in relation to linguistic proficiency levels, and the proof that collocational gains can be quantified following both proficiency levels and word frequency bands, this study lays the basic groundwork for developing a collocationbased syllabus. Considering both linguistic proficiency and word bands for productive knowledge of collocations, as suggested by Nizonkiza and Van de Poel (2014), seems to be warranted and could contribute enormously to the heated debate on which collocations to teach in L2/FL contexts.

In summary, the study satisfactorily answers the initial research questions and points to the conclusions that: (i) receptive knowledge of collocations grows as EFL proficiency develops; (ii) receptive knowledge of collocations added from one level of proficiency to another can be quantified; and (iii) receptive knowledge of collocations varies across word frequency bands.

The study has also raised other questions worth exploring in further research. Firstly, while it was proven that receptive knowledge of collocations grows more significantly at lower EFL proficiency levels, the study only included a few levels of proficiency (beginners, postbeginners, and low-intermediates) and concluded that collocational growth from one level to another is not exactly the same. Therefore, collocational growth deserves to be explored further in a follow-up study ideally including all levels of proficiency, from very beginners up to the most advanced. Following the non-linear nature of vocabulary acquisition in general (Laufer 1998, Laufer and Paribahkt 1998, Meara 1996, Melka 1997, Read 2004), involving more participants would allow for monitoring of collocational growth and would shed more light on what exactly happens as receptive knowledge of collocations develops, ultimately allowing for predictions of how much knowledge is added at which level of proficiency.

Secondly, this study is semi-longitudinal, and it is my view that studying one group longitudinally would give more detailed observations on receptive growth of collocational knowledge. Finally, the major limitation of this study is that it did not test receptive knowledge of participants' general vocabulary. As research evidence indicates that collocational knowledge develops slowly (Laufer and Waldman 2011, Nesselhauf 2005), testing receptive knowledge of collocations in comparison with receptive knowledge of vocabulary in general in another study could shed even more light on collocational growth. 


\section{Acknowledgements}

This study was completed thanks to the great contribution of Prof. Kris Van de Poel from the University of Antwerp, who provided constructive criticism from the design of instruments used for data collection up to the present stage. I owe her more than I can express. Many thanks also to Prof. Piet Swanepoel from Unisa for his comments on the final draft of the paper. I am greatly indebted to Rebecca Chick from Trinity College London for her invaluable assistance in the development of the collocation test. Finally, Daniel Sossi, who proofread the final manuscript, also deserves a special mention.

\section{References}

Allen, R.E. (Ed.) 1990. The concise Oxford dictionary. Oxford: Oxford University Press.

Barfield, A. 2003. Collocation recognition and production: Research insights. Tokyo: Chuo University.

Barfield, A. 2009. Following individual L2 collocation development over time. In A. Barfield and H. Gyllstad (Eds.) Researching collocations in another language. New York: Palgrave Macmillan. pp. 208-223.

Barfield, A. and H. Gyllstad (Eds.) 2009. Researching collocations in another language. New York: Palgrave Macmillan.

Boers, F. and S. Lindstromberg. 2009. Optimizing a lexical approach to instructed language acquisition. New York: Palgrave Macmillan.

Boers, F., J. Eyckmans, J. Kappel, H. Stengers and M. Demecheleer. 2006. Formulaic sequences and perceived oral proficiency: Putting a Lexical Approach to the test. Language Teaching Research 10(3): 245-261.

Boers, F., S. Lindstromberg, J. Littlemore, H. Stengers and J. Eyckmans. 2008. Variables in the mnemonic effectiveness of pictorial elucidation. In F. Boers and S. Lindstromberg (Eds.) Cognitive linguistic approaches to teaching vocabulary and pedagogy. Berlin: Mouton de Gruyter. pp. 189-218.

Collins. 1995. Collins COBUILD English collocations (CD-ROM). London: HarperCollins.

Coxhead, A. 2000. A new academic word list. TESOL Quarterly 34(2): 213-239.

Dagnelie, P. 1992. Principes d'expérimentation. Gembloux: Presses Agronomiques de Gembloux.

Dictionary.com. 2009. Available online: http://dictionary.reference.com/browse/ (Accessed 5 November 2009).

Ebel, R.L. 1979. Essentials of education measurement. New Jersey: Prentice Hall. 
Granger, S. 1998. Prefabricated patterns in advanced EFL writing: Collocations and formulae. In A.P. Cowie (Ed.) Phraseology: Theory, analysis and applications. Oxford: Oxford University Press. pp. 145-160.

Granger, S. and F. Meunier (Eds.) 2008. Phraseology. An interdisciplinary perspective. Amsterdam: John Benjamins Publishing Company.

Green, R. 2013. Statistical analyses for language testers. Basingstoke: Palgrave Macmillan.

Gyllstad, H. 2007. Testing English Collocations: Developing Receptive Tests for Use with Advanced Swedish Learners. Unpublished $\mathrm{PhD}$ dissertation, Lund University.

Gyllstad, H. 2009. Designing and evaluating tests of receptive collocation knowledge: COLLEX and COLLMATCH. In A. Barfield and H. Gyllstad (Eds.) Researching collocations in another language. New York: Palgrave Macmillan. pp. 153-170.

Howarth, P. 1998. Phraseology of second language proficiency. Applied Linguistics 19(1): 24-44.

Jiang, J. 2009. Designing pedagogic materials to improve awareness and productive use of L2 collocations. In A. Barfield and H. Gyllstad (Eds.) Researching collocations in another language. New York: Palgrave Macmillan. pp. 99-113.

Keshavarz, M.H. and H. Salimi. 2007. Collocational competence and cloze test performance: A study of Iranian EFL learners. International Journal of Applied Linguistics 17(1): 81-92.

Laufer, B. 1998. The development of passive and active vocabulary in a second language: Same or different? Applied Linguistics 19(2): 255-271.

Laufer, B. and S. Paribakht. 1998. The relationship between passive and active vocabularies: Effects of language learning contexts. Language Learning 48(3): 365-391.

Laufer, B. and G.C. Ravenhorst-Kalovski. 2010. Lexical threshold revisited: Lexical text coverage, learners' vocabulary size and reading comprehension. Reading in a Foreign Language 22(1): 15-30.

Laufer, B. and T. Waldman. 2011. Verb-noun collocations in second language writing: A corpus analysis of learners' English. Language Learning 61(2): 647-672.

Lea, D., J. Crowther and S. Dignen (Eds.) 2002. Oxford collocations dictionary for students of English. Oxford: Oxford University Press.

Lewis, M. 1993. The Lexical Approach: The state of ELT and the way forward. Hove: Language Teaching Publications.

Lewis, M. 1997. Implementing the Lexical Approach: Putting theory into practice. Hove: Language Teaching Publications. 
Lewis, M. 2000. Teaching collocations: Further development in the Lexical Approach. Hove: Language Teaching Publications.

Martyńska, M. 2004. Do English language learners know collocations? Investigationes Linguisticae 11: 2-12.

Meara, P. 1996. The dimensions of lexical competence. In G. Brown, K. Malmkjaer and J. Williams (Eds.) Competence and performance in language learning. Cambridge: Cambridge University Press. pp. 35-53.

Melka, F. 1997. Receptive versus productive vocabulary. In N. Schmitt and M. McCarthy (Eds.) Vocabulary: Description, acquisition, and pedagogy. Cambridge: Cambridge University Press. pp. 84-102.

Meunier, F. and S. Granger (Eds.) 2008. Phraseology in foreign language learning and teaching. Amsterdam: John Benjamins Publishing Company.

Mochizuki, M. 2002. Exploration of two aspects of vocabulary knowledge: Paradigmatic and collocational. Annual Review of English Language Education in Japan 13: 121-129.

Nation, P. 1983. Testing and teaching vocabulary. Guidelines 5(1): 12-25.

Nation, P. 1990. Teaching and learning vocabulary. Rowley, MA: Newbury House.

Nation, P. 2001. Learning vocabulary in another language. Cambridge: Cambridge University Press.

Nation, P. 2006. How large a vocabulary is needed for reading and listening? Canadian Modern Language Review 63(1): 59-82.

Nation, P. and D. Beglar. 2007. A vocabulary size test. The Language Teacher 31(7): 9-13.

Nattinger, J.R. and J.S. DeCarrico. 1992. Lexical phrases and language teaching. Oxford: Oxford University Press.

Nesselhauf, N. 2005. Collocations in a learner corpus. Amsterdam: John Benjamins Publishing Company.

Nizonkiza, D. 2011. The relationship between lexical competence, collocational competence, and second language proficiency. English Text Construction 4(1): 113-146.

Nizonkiza, D. and K. Van de Poel. 2014. Teachability of collocations: The role of word frequency counts. Southern African Linguistics and Applied Language Studies 32(1): 301-316.

Pallant, J. 2007. SPSS survival manual. Buckingham and Philadelphia: Open University Press. 
Pawley, A. and F.H. Syder. 1983. Two puzzles for linguistic theory: Nativelike selection and nativelike fluency. In J.C. Richards and R.W. Schmidt (Eds.) Language and communication. London: Longman. pp. 191-227.

Read, J. 1993. The development of a new measure of L2 vocabulary knowledge. Language Testing 10(3): 355-371.

Read, J. 1997. Assessing vocabulary in second language. In C. Clapham and D. Corson (Eds.) Encyclopaedia of language and education (volume 7): Language testing and assessment. Dordrecht: Kluwer Academic Publishers. pp. 90-98.

Read, J. 2000. Assessing vocabulary. Cambridge: Cambridge University Press.

Read, J. 2004. Plumbing the depths: How should the construct of vocabulary knowledge be defined? In P. Bogaards and L. Laufer (Eds.) Vocabulary in second language. Amsterdam: John Benjamins Publishing Company. pp. 209-227.

Schmitt, N. 1998. Measuring collocational knowledge: Key issues and an experimental assessment procedure. ITL Review of Applied Linguistics 119-120: 27-47.

Schmitt, N. and P. Meara. 1997. Researching vocabulary through a word knowledge framework: Word associations and verbal suffixes. Studies in Second Language Acquisition 19(1): 17-36.

Schmitt, N., D. Schmitt and C. Clapham. 2001. Developing and exploring the behaviour of two new versions of the Vocabulary Levels Test. Language Testing 18(1): 55-88.

Sinclair, J. 1991. Corpus, concordance, collocation. Oxford: Oxford University Press.

Singleton, D. 1999. Exploring the second language mental lexicon. Cambridge: Cambridge University Press.

West, M. 1953. A general service list of English words. London: Longman.

Willis, D. 1990. The lexical syllabus: A new approach to language teaching. London: Collins COBUILD.

Wray, A. 2002. Formulaic language and the lexicon. Cambridge: Cambridge University Press.

Ying, Y. and M. O'Neill. 2009. Collocation learning through an 'AWARE' approach: Learner perspectives and learning process. In A. Barfield and H. Gyllstad (Eds.) Researching collocations in another language. New York: Palgrave Macmillan. pp. 181-193.

Zhong, H. and D. Hirsh. 2009. Vocabulary growth in English as a foreign language context. University of Sydney Papers in TESOL 4: 85-113. 


\section{Appendices}

\section{Appendix A: Collocation test}

Universiteit

Antwerpen

\section{Receptive Collocation Test}

Name:

Date:

Level of study (year):

Start hour:

University:

End hour:

Instruction: One word has been deleted in each of the sentences below. Among the three words given, only one is appropriate, underline it.

Example: She is conducting campaigns to new clients.
a) attract
b) seduce
c) tempt

She is conducting campaigns to new clients.
a) attract
b) seduce
c) tempt

1. I ............ no intention of changing jobs because I am happy where I am.
a) have
b) possess
c) hold

2. Enemy planes were seen to bombs along the railway line.
a) descend
b) drop
c) fall

3. They always

a $10 \%$ commission on every sold encyclopaedia.
a) reimburse
b) reward
c) pay

4. I wonder, this unusual building seems to barely the definition of a house.
a) meet
b) fit
c) conform

5. Better your energy and not waste time trying to persuade people who are not interested.
a) save
b) economise
c) rescue

6. She asked him if he could a secret before telling him the horrible story.
a) retain
b) reserve
c) keep

7. Great care is being taken to the accuracy of research data with good planning, several revisions and rewrites as part of the procedure.
a) protect
b) ensure
c) secure

8. She felt she would a terrible mess of her life if she were to throw everything overboard now.
a) make
b) form
c) build 
9. They did not the permit for a street demonstration against university fees which they had applied for a couple of months ago.
a) win
b) get
c) acquire

10. Her appointment will the gap created when the marketing manager left.
a) supply
b) complete
c) fill

11. They held celebrations to
a) glorify
b) mark the anniversary of Mozart's death.

12. It is common practice that when a song ends, the performer has to a bow.
a) take
b) procure
c) acquire

13. They plan to congratulations to Tony on his new job and bought a nice card.
a) forward
b) send
c) transmit

14. We could a faint echo, before it slowly died away.
a) perceive
b) attend
c) hear

15. Victory will glory, fame, and riches to the football team.
a) guide
b) transport
c) bring

16. She inherited all the family precious stones, but she does not like to
a) bear
b) wear
c) carry

17. In May and June, females leave the males to
a) create
b) build
c) establish

18. She joined the navy where she expects to
a) reach
b) strike
c) hit

19. He is a person who can his soul to the devil provided he gets money.
a) sell
b) exchange
c) vend

20. Why didn't the referee the whistle just before he shot the goal; it would have prevented the clash between rival supporters.
a) hit
b) blow
c) slap

21. When she got pregnant at the age of 16 , she decided to an abortion.
a) endure
b) undergo
c) have

22. The estate expects to an auction to raise money.
a) hold
b) possess
c) contain

23. Our party should diversity, not division, in order to attract new members.
a) practise
b) urge
c) encourage

24. How do you the discrepancies between the money and the receipts?
a) elucidate
b) explicate
c) explain

25. Jumbo jets somehow the glamour of the transatlantic liner which has an impact on the number of passengers.
a) require
b) miss
c) lack

26. She had a short time to dress and
a) spread on
b) apply
c) lay jewellery. a nest and incubate their eggs. 
27. The burglars had to a pane of the front window to enter the house.
a) fracture
b) break
c) crack

28. He vowed to revenge on the man who had killed his brother.
a) take
b) seize
c) catch

29. They have decided to the catwalk stereotype of the skinny model.
a) doubt
b) challenge
c) question

30. They called on the government to help .... native wildlife as a response to the major environmental concerns of the century.
a) protect
b) shelter
c) defend

31. She was hoping she would not have to
a) donate
b) give
c) grant

32. I can't any conclusions from their vague observations.
a) attain
b) reach
c) hit

33. She had to some compensation for the damages she had caused.
a) pay
b) reimburse
c) reward

34. With the new computer, you can access to all the files.
a) have
b) possess
c) own

35. The mechanic can the necessary adjustments to the broken engine.
a) build
b) create
c) make

36. Many universities in the UK special fees to overseas students.
a) demand
b) ask
c) charge

37. His sound argument will the foundations for future cooperation between the two countries.
a) deposit
b) lay
c) put

38. We have to the safety guidelines laid down by the government.
a) follow
b) track
c) pursue

39. It is the duty of the local community to
a) provide
b) host
c) render

40. He was found to from clinical depression after several months of hospitalisation.
a) experience
b) endure
c) suffer 
Appendix B: Correlative links between TOEFL and collocation test

\begin{tabular}{|c|c|c|c|c|c|c|c|}
\hline & & TOEFLTOT & $\begin{array}{l}2000- \\
\text { word } \\
\text { level }\end{array}$ & $\begin{array}{l}3000- \\
\text { word } \\
\text { level }\end{array}$ & $\begin{array}{l}5000- \\
\text { word } \\
\text { level }\end{array}$ & $\mathrm{AW}$ list & TOTCOLLOCATION \\
\hline \multirow{3}{*}{ TOEFLTOT } & $\begin{array}{l}\text { Pearson } \\
\text { Correlation }\end{array}$ & 1 & $.317^{* *}$ & $.204^{*}$ & $.527^{* *}$ & $.626^{* *}$ & $.621^{* *}$ \\
\hline & $\begin{array}{l}\text { Sig. } \\
\text { tailed })\end{array}$ & & .002 & .045 & .000 & .000 & .000 \\
\hline & $\mathrm{N}$ & 97 & 97 & 97 & 97 & 97 & 97 \\
\hline \multirow{3}{*}{ 2000-word level } & $\begin{array}{l}\text { Pearson } \\
\text { Correlation }\end{array}$ & $.317^{* *}$ & 1 & $.209^{*}$ & $.265^{* *}$ & $.260^{* *}$ & $.626^{* *}$ \\
\hline & $\begin{array}{l}\text { Sig. } \\
\text { tailed })\end{array}$ & .002 & & .040 & .009 & .010 & .000 \\
\hline & $\mathrm{N}$ & 97 & 97 & 97 & 97 & 97 & 97 \\
\hline \multirow{3}{*}{ 3000-word level } & $\begin{array}{l}\text { Pearson } \\
\text { Correlation }\end{array}$ & $.204^{*}$ & $.209^{*}$ & 1 & .194 & $.262^{* *}$ & $.597^{* *}$ \\
\hline & $\begin{array}{l}\text { Sig. } \\
\text { tailed) }\end{array}$ & .045 & .040 & & .057 & .010 & .000 \\
\hline & $\mathrm{N}$ & 97 & 97 & 97 & 97 & 97 & 97 \\
\hline \multirow{3}{*}{ 5000-word level } & $\begin{array}{l}\text { Pearson } \\
\text { Correlation }\end{array}$ & $.527^{* *}$ & $.265^{* *}$ & .194 & 1 & $.546^{* *}$ & $.728^{* *}$ \\
\hline & $\begin{array}{l}\text { Sig. } \\
\text { tailed) }\end{array}$ & .000 & .009 & .057 & & .000 & .000 \\
\hline & $\mathrm{N}$ & 97 & 97 & 97 & 97 & 97 & 97 \\
\hline \multirow{3}{*}{ AW list } & $\begin{array}{l}\text { Pearson } \\
\text { Correlation }\end{array}$ & $.626^{* *}$ & $.260^{* *}$ & $.262^{* *}$ & $.546^{* *}$ & 1 & $.780^{* *}$ \\
\hline & $\begin{array}{l}\text { Sig. } \\
\text { tailed) }\end{array}$ & .000 & .010 & .010 & .000 & & .000 \\
\hline & $\mathrm{N}$ & 97 & 97 & 97 & 97 & 97 & 97 \\
\hline \multirow{3}{*}{ TOTCOLLOCATION } & $\begin{array}{l}\text { Pearson } \\
\text { Correlation }\end{array}$ & $.621^{* *}$ & $.626^{* *}$ & $.597^{* *}$ & $.728^{* *}$ & $.780^{* *}$ & 1 \\
\hline & $\begin{array}{l}\text { Sig. } \\
\text { tailed })\end{array}$ & .000 & .000 & .000 & .000 & .000 & \\
\hline & $\mathrm{N}$ & 97 & 97 & 97 & 97 & 97 & 97 \\
\hline
\end{tabular}

* Correlation is significant at the 0.05 level (2-tailed).

** Correlation is significant at the 0.01 level (2-tailed). 